\title{
Resilience Concept in Indonesian Small Town Development and Planning: a Case of Lasem, Central Java
}

\author{
Jawoto Sih Setyono ${ }^{1, *}$, Wiwandari Handayani ${ }^{1}$,Iwan Rudiarto $^{1}$, and Landung Esariti ${ }^{1}$ \\ ${ }^{1}$ Department of Urban and Regional Planning, Diponegoro University, Semarang, Indonesia
}

\begin{abstract}
Rapid urbanization in developing countries has brought some unprecedented consequences in economic, social, and most notably environmental aspects. Many cities have to be dealing with the challenges of vulnerability as the risk of disasters increases. In responding to the challenges, the concept of urban resilience has been applied as an important part of the current development policies in many countries. In Indonesia, the current spatial policy framework has underlined the importance of integrating vulnerability and environmental carrying capacity into spatial planning document. However, attention has been mostly given to metropolitan or large urban areas. This policy imbalance has put aside the problems faced by smaller urban areas or small cities, although the growing importance of small urban areas or cities is widely understood. In fact, the problems faced by small cities are not less important compared to that of large cities or metropolitan regions, especially those which are in coastal regions. This research aims at analysing how the development and planning of small cities in coastal areas considers the resilience concept. This research applied qualitative methods based on content analysis of planning documents and secondary data. This study selected Lasem, a small urban area in eastern coastal region of Central Java with some 50,000 population, as a case. This research found that the current spatial policy framework is lacking in integrating vulnerability and resilience dimension in the policy and development processes. The research recommended some key important factors to be integrated in the future urban development model.
\end{abstract}

\section{Introduction}

Small cities and towns are important places of living for urban residents, as half of the urban population around the world resides in these urban areas [1]. The population of small towns, urban areas with population of 500.000 people or less, is $25 \%$ of the world's total population. Of this number, almost $50 \%$ are in Asia [2]. In other words, urban dwellers in Asia generally reside in small towns. In the case of Indonesia, as stated in the UN Population Division [2], in 2000 the number of urban residents living in small towns of

\footnotetext{
*Corresponding author: jawoto@pwk.undip.ac.id
} 
500.000 population or less is $68 \%$ of the total urban population. This proportion increases when compared to the conditions in 1980 , where there were about $57 \%$ of urban dwellers residing in the small towns.

Census data also show that the urban population growth of small towns in Indonesia is higher than that of big cities. As stated by [3], the urban population growth in many districts on the island of Java is higher than the cities that have been the reference for urbanization studies in Indonesia such as Jakarta, Bandung and Surabaya. This fact shows that in addition to the phenomenon of urbanization that leads to the formation of extended mega-urban regions as proposed by [4], the urbanization process also occurs in areas characterized by rural areas. Some scholars mention this phenomenon as extended urbanization, like the process that occurs in Cirebon and surrounding areas [5].

There are several challenges faced by small towns in Indonesia. First, most small towns in Indonesia do not have their own "government" [6]. The lacking in the governmentality has resulted in many urban problems, especially spatial problems that are not resolved properly. Secondly, the existence of a large city adjacent to the small towns has an impact on the development of the city. As a result, small towns tend not to develop independently as settlement centres. Third, development affairs are ineffective, especially in small towns that do not function as local government or district capitals.

Aside from the urban management perspectives, there have been factual problems faced by the small cities and towns in Indonesia, especially those which are located at coastal regions. Recent research shows that rapid rate of urbanization tends to increase the tendency of disaster risk in northern coastal region in Central Java where most of small towns are located [7]. The event of disasters such as flood, drought and tidal flooding have marked the development of the coastal cities in the province [8]. The current condition has led to increasing vulnerability for population living in the coastal cities. The risk of disaster has become even bigger as the impact of climate change started to take place in the region in recent years.

The challenges from both urban management and recent factual problems faced by small cities and town in Indonesia rise the question of how the policy framework has adequately addressed the problems. Furthermore, within the growing discussion that urban areas at all size should start to have greater resilience in responding to the unexpected shocks and stresses, how the small cities and towns consider the resilience concepts as part of their current and future development policies is interesting to study within the Indonesian urban context.

This research aims at analysing how the development and planning of small cities in coastal areas considers the resilience concept. This research was done by underlying proposition that policy framework, especially spatial policies, has been lacking in integrating the concept into policy process. It occurred because the current practice of spatial development policy in Indonesia has more emphasized and been mostly based on procedural and normative process. Legal and formal processes have somewhat hindered the initiatives to adopt new aspects of development which are not stated in the legal and formal framework.

This paper is structured into five sections. The first section provides introductory and background of the research. The following part discusses the theoretical framework of urban resilience from different perspectives. Short description of study area and methods used in the research are explained in the third section. The fourth part of this article elaborate results and synthesize findings. Some concluding remarks conclude the paper. 


\section{Theoretical Perspectives of Urban Resilience}

There have been disquiet discussion and debate on the term of resilience in scholarly journals. The term resilience has been widely used across disciplines recently, although it roots in physics and psychology [9]. Generally, resilience concept refers to the capacity of system, object or individual to be back its previous condition after disturbances. This concept underlines the importance of equilibrium as main element of resilience. This means that a resilient state occurs when something reaches equilibrium after shock and stress [9].

The adaptation of resilience concept into urban context has many perspectives and applications. The most common use of resilience concept is in the context of disasters and hazard, including the impact of climate change on urban areas. There are some concepts that try to bring resilience concept into a broader spectrum of urban context such the concept of social-ecological system (SES) resilience. Some scholars also elaborate the resilience concept in detail such as the concept of urban economic resilience or urban institutional resilience. Later, rather than to define resilience in terms of to what or $\boldsymbol{o f}$ what, there is a proposal to develop a more general concept in the term of spatial resilience [10].

In the context planning, the question of how to integrate resilience concept into urban planning is seemingly unanswerable, especially in the context of urban development in developing countries. Many tools and methods have been developed to assist planners and policy makers but the difficulty of making the concept works is still prevailed. Many tools and methods proposed available to use are mostly based on certain objective such as reducing disaster risk, adapting to climate change, or resolving from economic problems.

Sharifi and Yamagata [9] propose a more general framework to assist analysing the urban resilience condition. The urban resilience matrix is developed to help facilitating planning process by understanding the key components of urban resilience to be considered into planning document. As shown in Figure, the concept of urban resilience consists of for components (prepare, absorb, recover, and adapt) that cover four important systems or domains, i.e. physical, informal, cognitive and social.

\begin{tabular}{|l|l|l|l|l|}
\cline { 2 - 5 } \multicolumn{1}{c|}{} & Prepare & Absorb & Recover & Adapt \\
\hline Physical & & & & \\
\hline Information & & & & \\
\hline Cognitive & & & & \\
\hline Social & & & & \\
\cline { 2 - 5 }
\end{tabular}

Fig. 1. Urban resilience matrix

\section{Study Area, Data and Method}

This research selected Lasem, a small town with population of less than 50,000 people, as a case. The selection of this small town was based on some considerations. Firstly, the town are located at Central Java coastal areas which recently suffer from the impact of sea level rise [8]. Secondly, Lasem is one of the first urban settlements on the coastal region so that it is culturally rich because of interaction between indigenous people with people from other countries during Dutch colonization period. Thirdly, the current development of new 
cement industry in the town hinterland can potentially change the structure of the town, not only in economic but also in spatial and social terms. Figure 2 provides the context of Lasem in the region of Rembang and Central Java.

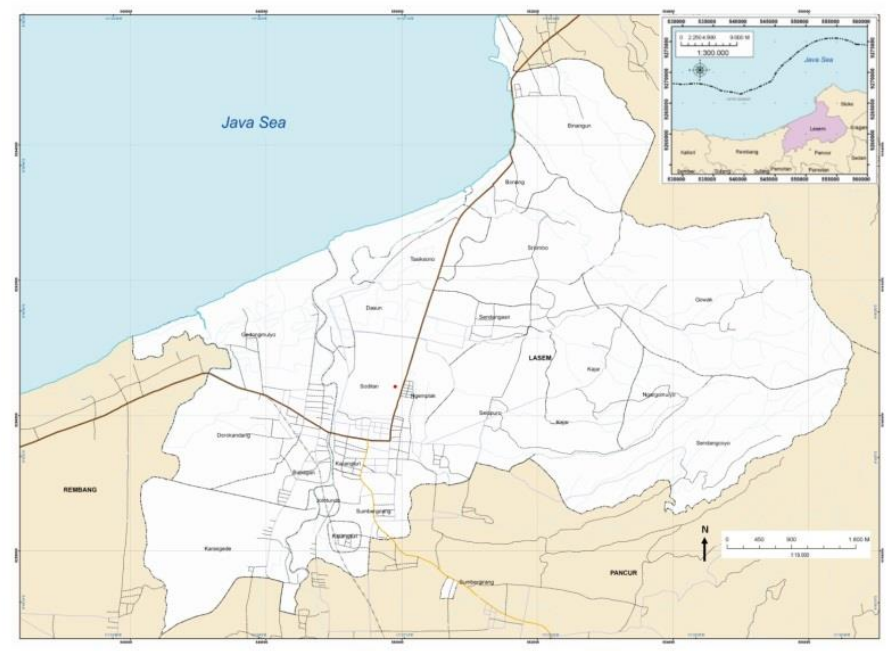

Fig. 2. Lasem as study area

Data in this research were mainly from policy documents or policy study documents. The policy document in this case is the document of the City Spatial Plan (RTRW) in the case. In Indonesia, the RTRW documents have become publication that are legally binding because they have been outlined in the form of a Regional Regulation (Perda). The policy study document is the result of spatial planning studies on small town in the case. Unlike the RTRW document, this planning document still has no legal basis, although in practice it is often used as a reference in directing urban development policies. In addition to the data, this study also used secondary data which mainly relate to urban development indicators. The data were gathered from the Central Bureau of Statistics and other relevant agencies at local government such as Planning Board (Bappeda) and Public Works Agency.

In addition to document analysis, several interviews were conducted to obtain additional information and explore management experiences and urban development issues. In this study, the interview was not the main instrument because it was only applied to comprehend the results from document review and secondary data analysis. Interviews were targeted the main actors of development at the district level, who were regarded as key informant to deepen the analysis. The interviews were conducted in an unstructured way and in practice also involved other staff at the sub-district government level, such as head of sub-district and head of village.

\section{Results and Discussions}

Lasem is part of Rembang Regency, a district within Central Java Province which has direct boundary with East Java Province. Rembang region has been experiencing with multi-hazard situation as landslide, fog, flood, and drought are common disaster in some sub-districts. In 2000 for example, drought occurred in almost all coastal districts. Coastal areas are usually prone to tidal regular tidal flooding. In Lasem alone, during 2011-2016, there have been 13 events of flooding, exposing 9 villages in the town [8]. Along with tidal flooding, the town recently has also been exposed to inundation. The inundation mostly 
happens not only because of higher/unpredictable rainfall but also because of poor drainage system and bad waste management in settlement as well as commercial area in the city centre.

Data show that the event of disaster in the town tends to decrease recently. The reduction of disaster risk in Lasem in partly because of some intervention made by government and local people. The intervention can be categorised into infrastructure development program, spatial planning and controlling, disaster risk reduction program, and environmental management. However, not all interventions have direct impact to the reduction of risk, especially those which relate to spatial policies. As Handayani et al. [8] point out that, most of villages within Lasem administrative boundary are classified as rather vulnerable or worse. This condition does not seem to be considered adequately in the proposed spatial plan for Lasem.

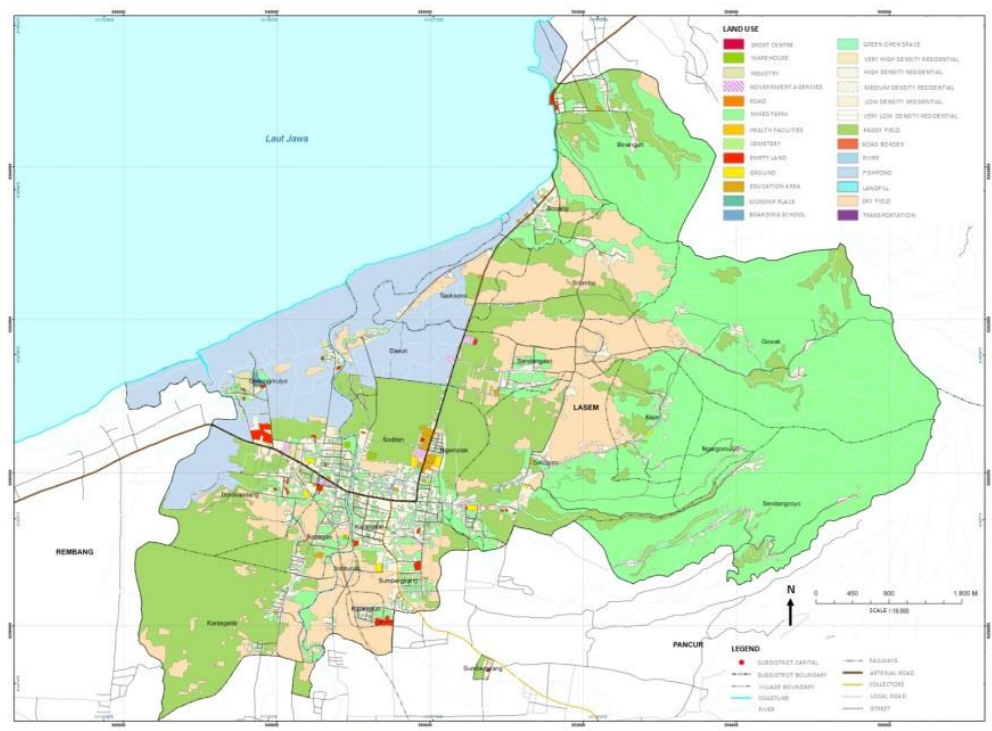

Fig. 3. Land use of Lasem

One of the spatial planning initiatives that put Lasem as the policy target was the formulation of detail spatial plan in 2012. The formulation of the plan was part of the direct consequences of the enactment of Local Law concerning Regional Spatial Plan of Rembang region in 2011. According to the Indonesian national system of spatial planning as stated in Spatial Planning Act of 2007, urban areas that were designated as sub regional centre should develop their detail spatial plan as the main instrument of development control in the urban areas. The spatial policy paper of Lasem consisted of future directions to transform the existing urban land use (see Figure 3) into the planned condition to be achieved in twenty year (2032).

Comparing the existing land use with proposed Lasem land use plan may lead to some interesting findings. In the planning objective, the future of Lasem is more favour on economic development rather than sustaining urban development. Addressing resilience or other objectives which may have association with sustainability and reducing risks are not mentioned in the planning document. However, in land use plan section, the proportion of land to designated as conservation areas is quite high, as more than $35 \%$ of the total area are classified as protected areas (kawasan lindung) - see Figure 4 for detail. This figure indicates inconsistency between planning objective and zoning of land use. 


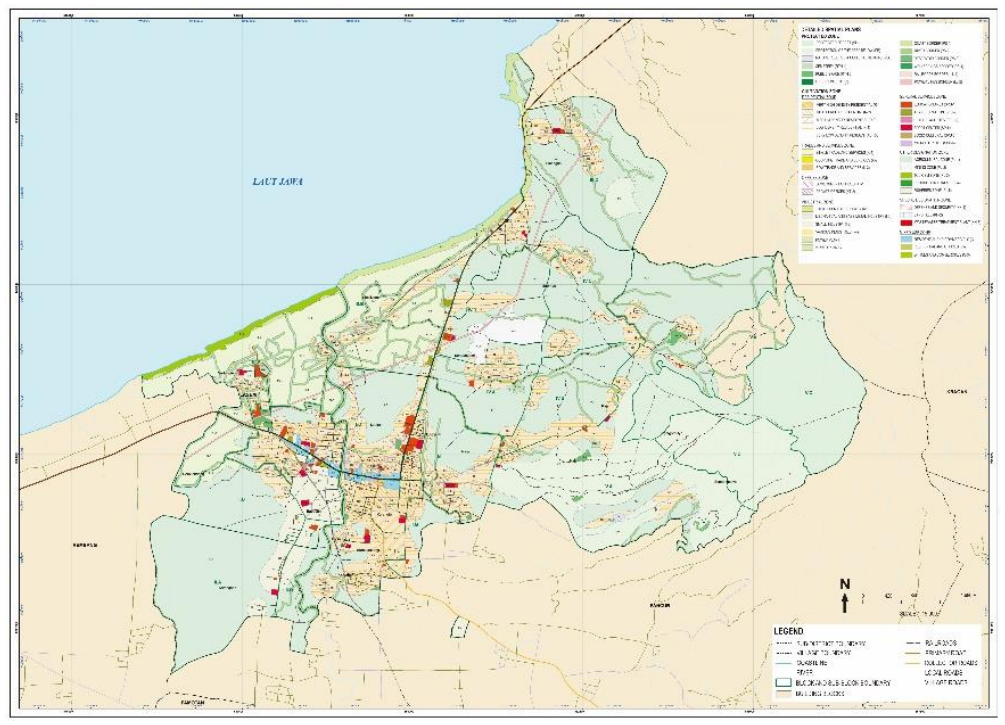

Fig. 4. Lasem proposed land use plan 2032

Looking further the planning document, it is found that implementation directions that follow planned land use also do not provide proper guidelines for development that considers the principles of urban resilience. As [9] mention in the previous section, urban resilience concept can be view from four elements, i.e. prepare, absorb, recover and adapt. The planning implementation guidelines do not point out how the vulnerability areas in Lasem should be managed. Some conventional measures of development control such as building coverage ratio, setback and other instrument were stated in the document. However, from the theoretical perspectives, these instruments have less importance in fostering resilience concept in the planning document.

From the content analysis of the document, it is found that there are only very few parts of spatial planning scheme in Lasem which adequately mentioned or even considered the concept of urban resilience in its proposed policies. While this situation is not ideal enough for the city with relatively high degree of vulnerability, but it can also be regarded common in recent spatial development policy process in Indonesia. [11] state that there are both overlapping and mismatch between spatial planning and development planning in Indonesian regional and local development policy framework. As the consequences, both policies are like contesting each other although it should be linked and integrated.

\section{Conclusion}

The case from Lasem in Central Java provides the opportunity to understand the current problems and challenges faced by small cities or towns in Indonesia in general. It is found that along with the urban management issues, there have been some aspects in the small cities and towns development which are not responded properly in the planning documents. The Lasem case shows that despite its vulnerability status in the town development path, the proposed spatial policies do not provide enough guidance to solve the problem albeit the broader discussion of resilience concept starts to take place in many forums. The challenges need to be resolved by adopting alternative policy formulation framework which 
enables local government to adopt new policy process which can cope with the future problems, especially for the cities in coastal areas which will be exposed by future hazards.

\section{Acknowledgments}

This paper is part of research findings funded by a grant provided by Ministry of Research, Technology and Higher Education, Indonesia. The authors would like to thank Centre for Research and Community Services, Diponegoro University for administering the funding so that the team can do all research activities very well. However, all contents of this publication are solely the responsibility of the authors.

\section{References}

1. Tacoli, C. The Earthcan Reader in Rural-Urban Linkagesm (Earthscan Publication, 2006)

2. United Nations. World Urbanization Prospects 2014: Highlights. (United Nations Publications, 2015)

3. Firman, T., Kombaitan, B., \& Pradono, P. (2007). J. Urban Policy and Research 25, 4

4. Ginsburg, N. S., Koppel, B., \& McGee, T. G. The Extended Metropolis: Settlement Transition in Asia, University of Hawaii Press, 1991)

5. Fahmi, F. Z., Hudalah, D., Rahayu, P., \& Woltjer, J. J. Habitat International 42 (2014)

6. Niessen, N. Municipal Government in Indonesia: Policy, Law, And Practice of Decentralization and Urban Spatial Planning (No. 77) (Research School CNWS, School of Asian, African, and Amerindian Studies, Universiteit Leiden, 1999)

7. Rudiarto, I., Handayani, W. and Setyono, J.S., 2018. J. Land 7, 1

8. Handayani, W., Rudiarto, I., Setyono, J.S., Chigbu, U.E. and Sukmawati, A.M.A., 2017. J. Advances in Climate Change Research 8, 4

9. Sharifi, A. and Yamagata, Y. Resilience-Oriented Urban Planning. In ResilienceOriented Urban Planning (pp. 3-27) (Springer, Cham, 2018)

10. Cumming, G.S. J. Landscape Ecology 26, 7 (2011)

11. Handayani, W., Rudiarto, I., Setyono, J., FOLEY, D., Fisher, M. (forthcoming) (Operationalizing resilience: A content analysis of flood disaster planning in two coastal cities of Central Java, Indonesia) 
